\title{
Knowledge of basic epidemiological and statistical concepts among doctors in selected Sri Lankan hospitals \\ H.T.C.S. Abeysena ${ }^{1}$, P. L. Jayawardana ${ }^{1}$, A. R. Wickremasinghe ${ }^{2}$, U. Wickramasinghe ${ }^{3}$
}

\begin{abstract}
Introduction

This study was conducted to describe the ability to comprehend basic epidemiologic and statistical concepts among doctors in selected hospitals in the Western Province.

Methodology
\end{abstract}

A cross-sectional descriptive study was conducted during January to February, 2008. The study population consisted of 315 doctors - 43 (13.7\%) specialists, 50 (16\%) postgraduate trainees (PG) and $222(70.3 \%)$ grade medical officers. A self administered questionnaire was used to assess perceived knowledge on selected epidemiologic and statistical concepts/parameters and two problem based questions which tested the ability to apply knowledge were used. Data were analyzed calculating the proportion who perceived to have good knowledge regarding each concept. Logistic regression was applied to test for differences in good knowledge between different groups of subjects.

Results

More than $75 \%$ of the respondents claimed to have good knowledge on prevalence, sensitivity, specificity and case control studies. Less than $50 \%$ of them had good knowledge on risk difference, number needed to treat, systematic reviews, meta-analysis, $\mathrm{p}$-value and $95 \%$ confidence intervals.

Male doctors had a significantly higher good knowledge than female doctors $(p<0.001)$, and those who read medical journals regularly than those who did not $(\mathrm{p}<0.05)$. Specialists and PG trainees had a significantly higher good knowledge $(\mathrm{p}<0.001)$ than grade medical officers. Correct answers of the respondents to the two problem based questions were $25 \%$ $(\mathrm{n}=79)$ and $15.8 \%(\mathrm{n}=50)$, respectively.

Conclusion

Even though some doctors claimed to have a good knowledge with regard to selected epidemiologic and statistical concepts, their ability to apply their knowledge was poor.

\section{Introduction}

Evidence based healthcare and evidence based medicine (EBM) emphasize that every decision in healthcare should be made in the context of best evidence available currently. The practice of EBM improves the patient management process and decreases healthcare costs with a resultant improvement in healthcare quality.
Critical appraisal skills are one of the basic steps in the process of practicing EBM. Therefore, clinicians and healthcare managers need to read the literature regularly and possess the ability to interpret journal articles and evidence based summaries for decision making. Thus familiarity with randomized controlled trials (RCTs) and meta-analyses is essential to practice EBM. ${ }^{1}$

1. Senior Lecturer, Department of Public Health, Faculty of Medicine,University of Kelaniya

2.Professor of Community Medicine,Department of Public Health, Faculty of Medicne,University of Kelaniya

3.Demonstrator, Department of Public Health, Faculty of Medicine,University of Kelaniya 
In the majority of journal articles, statistics are utilized primarily for data description and hypothesis-testing ${ }^{2}$. Therefore, knowledge of basic biostatistics and study designs is important for reading and interpreting medical literature. ${ }^{2}$ Undergraduate and some postgraduate courses in the Postgraduate Institute of Medicine (PGIM) have included basic medical statistics and epidemiology in their curricula. Several studies have concluded that the knowledge of biostatistics of most doctors is so limited that they cannot be expected to draw right conclusions from the statistical analyses published in many medical journal articles. $^{3-5}$ Wulff reported that most residents lacked knowledge in biostatistics needed to interpret many of the results in published clinical research. ${ }^{3}$ West reported that $93 \%$ of doctors believed that biostatistics is an important part of EBM. ${ }^{6}$ A high correlation between knowledge of, attitudes regarding and professional use of RCTs and meta-analyses has been reported by De Vito. ${ }^{1}$ Horton $^{7}$ had reported that more than half of the articles used relatively sophisticated statistical methods such as survival analysis or multiple regression. This study also reported that there is a continued trend towards increased use of newer and complex analytical methods not typically included in introductory or second-level statistics courses. ${ }^{7}$ The use of more sophisticated statistical methods may challenge clinicians' comprehension of research findings which, as a consequence, could slow dissemination of study results. ${ }^{7,8}$ The objective of this study was to describe the perceived ability of doctors in selected hospitals in the Western Province of Sri Lanka to comprehend basic epidemiologic and statistical concepts.

\section{Methodology}

A cross-sectional descriptive study was carried out in four hospitals in Sri Lanka, namely, the National Hospital of Sri Lanka, the Colombo North Teaching Hospital, Ragama, the Chest Hospital, Welisara and the Rheumatology and Rehabilitation Hospital, Ragama. The study population consisted of 315 doctors. A pre-tested self-administered questionnaire was used to gather information on perceived knowledge on basic epidemiologic and statistical concepts.

Two problem based scenarios were given to assess the ability to apply knowledge on epidemiology and biostatistics. Scenario I was in reference to interpretation of mean difference, its $95 \%$ confidence interval and the statistical significance. Scenario II was in reference to interpretation of relative risk, its $95 \%$ confidence interval and the statistical significance. All the questionnaires were distributed personally by one of the authors and collected by them to minimize the non-response rate. A Likert scale was used to assess perceived knowledge. Each correct response received a score of one and an incorrect and a missing response a zero. The total score was computed by adding the individual scores which was expressed as a percentage of the maximum total score possible. All questions received the same weightage. A total score of $\geq 75 \%$ was defined as "good knowledge". The characteristics that were associated with "good knowledge" were assessed by applying the chi-squared test. 
Multiple logistic regression with backward elimination was applied for controlling confounders. A two-tailed probability of $<0.05$ was considered as statistically significant.

Ethical clearance was obtained from the Ethics Committee of the Faculty of Medicine, University of Kelaniya, Sri Lanka.

\section{Results}

The questionnaire was distributed among 407 doctors; of them, 315 responded giving a response rate of $77.4 \%$. The participants included $43 \quad(13.7 \%)$ specialists, $50(16 \%)$ postgraduate (PG) trainees and $222(70 \%)$ grade medical officers who did not have any postgraduate qualifications. The proportion of males was $53.7 \%(\mathrm{n}=168)$. The mean age was $38(\mathrm{SD} \pm 5.4)$ years and the median working experience was 6 (range 2 - 30) years (Table 1)

Table 1 - Characteristics of participants

\begin{tabular}{|c|c|}
\hline Characteristic & $\mathbf{n}$ \\
\hline \multicolumn{2}{|l|}{ Sex } \\
\hline Male & $168(53.7 \%)$ \\
\hline Female & $145(46.3 \%)$ \\
\hline \multicolumn{2}{|l|}{ Age } \\
\hline$<40$ years & $179(57.0 \%)$ \\
\hline$\geq 40$ years & $134(43.0 \%)$ \\
\hline \multicolumn{2}{|c|}{ Duration of service } \\
\hline$<5$ years & $126(41.0 \%)$ \\
\hline $5-9$ years & $103(33.0 \%)$ \\
\hline$\geq 10$ years & $81(26.0 \%)$ \\
\hline \multicolumn{2}{|c|}{ Work place } \\
\hline University & $27(8.8 \%)$ \\
\hline Health Ministry & $288(91.4 \%)$ \\
\hline \multicolumn{2}{|c|}{ Designation } \\
\hline Specialists & $43(13.5 \%)$ \\
\hline Postgradute trainees & $50(16.0 \%)$ \\
\hline Grade medical officers & $222(70.5 \%)$ \\
\hline \multicolumn{2}{|c|}{ Medical journals read regularly } \\
\hline Yes & $209(67.0 \%)$ \\
\hline No & $106(34.0 \%)$ \\
\hline
\end{tabular}

More than $75 \%$ of the respondents in the three groups had good perceived knowledge on prevalence, sensitivity, specificity and case control studies; $70 \%$ or more specialists and PG trainees had a good perceived knowledge on meta- analysis and p-values. Knowledge on odds ratio, relative risk and number needed to treat (NNT) was perceived to be good among $50-75 \%$ of specialists and PG trainees. 
Knowledge on risk difference was groups (Table 2). perceived to be poor among all three

Table 2 - Perceived knowledge of selected topics by designation of participants

\begin{tabular}{|c|c|c|c|c|}
\hline Variable & $\begin{array}{c}(\mathrm{N}=43) \\
n\end{array}$ & $\begin{array}{c}\begin{array}{c}\text { Postgraduate } \\
\text { trainees } \\
\\
(\mathbf{N}=\mathbf{5 0}) \\
\mathbf{n}\end{array} \\
\end{array}$ & $\begin{array}{c}\text { Grade } \\
\text { medical } \\
\text { officers } \\
(\mathrm{N}=222) \\
\mathbf{n}\end{array}$ & $\begin{array}{c}\text { Total } \\
\text { participant } \\
\left(\begin{array}{c}\mathbf{N}=\mathbf{3 1 5}) \\
\mathbf{n}\end{array}\right.\end{array}$ \\
\hline Prevalence & $36(83.7 \%)$ & $44(88.0 \%)$ & $169(76.0 \%)$ & $249(79.0 \%)$ \\
\hline P value & $34(79.0 \%)$ & $42(84.0 \%)$ & $75(33.8 \%)$ & $151(48.0 \%)$ \\
\hline Confidence interval & $26(60.5 \%)$ & $38(76.0 \%)$ & $82(37.0 \%)$ & $146(46.3 \%)$ \\
\hline Sensitivity & $40(93.0 \%)$ & $49(98.0 \%)$ & $173(78.0 \%)$ & $262(83.2 \%)$ \\
\hline Specificity & $39(90.7 \%)$ & $47(94.0 \%)$ & $170(76.6 \%)$ & $256(81.3 \%)$ \\
\hline Case control studies & $41(95.0 \%)$ & $50(100.0 \%)$ & $172(77.5 \%)$ & $263(83.5 \%)$ \\
\hline Odds ratio & $24(55.8 \%)$ & $34(68.0 \%)$ & $82(37.0 \%)$ & $140(44.4 \%)$ \\
\hline Relative risk & $27(63.0 \%)$ & $34(68.0 \%)$ & $114(51.4 \%)$ & $175(55.6 \%)$ \\
\hline Risk difference & $16(37.0 \%)$ & $24(48.0 \%)$ & $67(30.2 \%)$ & $107(34.0 \%)$ \\
\hline Number needed to treat & $25(58.0 \%)$ & $30(60.0 \%)$ & $84(37.8 \%)$ & $139(44.0 \%)$ \\
\hline Systematic Reviews & $35(81.4 \%)$ & $30(60.0 \%)$ & $83(37.4 \%)$ & $148(47.0 \%)$ \\
\hline Meta-analysis & $30(70.0 \%)$ & $38(76.0 \%)$ & $47(21.0 \%)$ & $115(36.5 \%)$ \\
\hline
\end{tabular}

The proportion of respondents who provided correct answers to the two problem based scenarios was $25 \%(\mathrm{n}=79)$ and $15.8 \%(\mathrm{n}=50)$ respectively (Table 3$)$.

Table 3 - Application of knowledge by designation of participants

\begin{tabular}{|c|c|c|c|c|c|}
\hline \multicolumn{2}{|c|}{ Scenarios } & $\begin{array}{c}\text { Specialists } \\
\begin{array}{c}(\mathrm{N}=43) \\
n\end{array}\end{array}$ & $\begin{array}{c}\text { Postraduate } \\
\text { trainees } \\
\left(\begin{array}{c}\mathbf{N}=50) \\
\mathbf{n}\end{array}\right.\end{array}$ & $\begin{array}{c}\text { Grade } \\
\text { medical } \\
\text { officers } \\
(\mathbf{N}=222) \\
\mathbf{n}\end{array}$ & $\begin{array}{c}\text { Total } \\
\text { participants } \\
\left(\begin{array}{c}\mathbf{N}=315) \\
\mathbf{n}\end{array}\right.\end{array}$ \\
\hline 1 & $\begin{array}{l}\text { Interpretation of mean } \\
\text { difference and } \\
\text { confidence interval }\end{array}$ & $16(37.2 \%)$ & $16(32 \%)$ & $47(21 \%)$ & $79(25 \%)$ \\
\hline II & $\begin{array}{l}\text { Interpretation of } \\
\text { relative risk and } \\
\text { confidence interval }\end{array}$ & $05(11.6 \%)$ & $12(24 \%)$ & $33(15 \%)$ & $50(15.8 \%)$ \\
\hline
\end{tabular}


The mean knowledge score of the sample was $57 \%$ (95\% CI: $53 \%$ - 60\%).

One hundred and fifteen $(36.5 \%)$ doctors had a "good knowledge". According to the bivariate analysis being a male (49\%; $\mathrm{n}=82)(\mathrm{p}<0.001)$. versus a female $(22 \%$; $\mathrm{n}=32$ ), being affiliated to the university ( $63 \% ; \mathrm{n}=17)[\mathrm{p}<0.01]$ versus being affiliated to the Ministry of Health (34\%; $\mathrm{n}=98$ ), being a specialist / PG trainee
$(61 \% ; \mathrm{n}=57)$ versus a grade medical officer $(26 \% ; \mathrm{n}=58)$ [p<0.001], having a work experience of $<5$ years $(48 \% ; n=60)$ versus $\geq 5$ years $(29 \%$; $-=53) \quad[\mathrm{p}<0.01]$ and regular reading of medical journals (46\%; $\mathrm{n}=96)$ ) $\mathrm{p}<0.001]$ than otherwise $(18 \% ; n=19)$ were the factors that were significantly associated with "good knowledge" [Table 4].

Table 4 - Unadjusted odds ratios for poor knowledge by participant characteristics

\begin{tabular}{|c|c|c|c|c|c|}
\hline \multirow[t]{2}{*}{ Characteristic } & \multicolumn{2}{|c|}{ Knowledge } & \multirow{2}{*}{$\begin{array}{l}\text { Odds } \\
\text { Ratio }\end{array}$} & \multirow{2}{*}{$\begin{array}{c}95 \% \\
\text { Confidence } \\
\text { Interval } \\
\end{array}$} & \multirow{2}{*}{$\begin{array}{c}\mathbf{P} \\
\text { value }\end{array}$} \\
\hline & $\begin{array}{c}\text { Good } \\
\mathbf{n}\end{array}$ & $\begin{array}{c}\text { Poor } \\
\text { n }\end{array}$ & & & \\
\hline \multicolumn{6}{|l|}{ Sex } \\
\hline Male & $82(49 \%)$ & $86(51 \%)$ & 0.30 & $0.18-0.50$ & $<0.001$ \\
\hline Female & $32(22 \%)$ & $113(78 \%)$ & & & \\
\hline \multicolumn{6}{|l|}{ Age } \\
\hline$<40$ years & $68(38 \%)$ & $111(62)$ & 0.85 & $0.53-1.36$ & $>0.05$ \\
\hline$\geq 40$ years & $46(34 \%)$ & $88(66)$ & & & \\
\hline \multicolumn{6}{|l|}{ Service } \\
\hline$<5$ years & $60(48 \%)$ & $66(52 \%)$ & 0.44 & $0.28-0.71$ & $<0.01$ \\
\hline$\geq 5$ years & $53(29 \%)$ & $131(71 \%)$ & & & \\
\hline \multicolumn{6}{|l|}{ Work place } \\
\hline University & $17(63 \%)$ & $10(37 \%)$ & 0.30 & $0.13-0.69$ & $<0.01$ \\
\hline Health Ministry & $98(34 \%)$ & $190(66 \%)$ & & & \\
\hline \multicolumn{6}{|l|}{ Designation } \\
\hline Specialist/ $\mathrm{PG}^{*}$ & $57(61 \%)$ & $36(39 \%)$ & 0.22 & $0.13-0.37$ & $<0.001$ \\
\hline Gr Med Off** & $58(26 \%)$ & $164(74 \%)$ & & & \\
\hline \multicolumn{6}{|c|}{ Reading medical journals regularly } \\
\hline Yes & $96(46 \%)$ & $113(54 \%)$ & 0.26 & $0.15-0.45$ & $<0.001$ \\
\hline No & $19(18 \%)$ & $87(82 \%)$ & & & \\
\hline
\end{tabular}

*Postgraduate trainee; ** Grade medical officer

In the multivariate analysis being a male $(<0.001)$ and a specialist or $\mathrm{PG}$ trainee $(\mathrm{p}<0.001)$ and regular reading of medical journals $(<0.001)$ were the factors that remained significantly associated with "good knowledge".

\section{Discussion}

Our study revealed that perceived knowledge on some epidemiologic concepts of all three groups was satisfactory. 
Specialists and PG trainees claimed higher perceived knowledge than grade medical officers. Despite a mean knowledge score of $57 \%$ among the total sample, the ability to interpret epidemiologic and statistical concepts was observed to be very poor.

Among Saudi Arabian doctors, correct responses for basic knowledge on sensitivity, specificity and odds ratios were $39 \%, 33 \%$ and $50 \%$ respectively. ${ }^{9}$ In this study, more than $80 \%$ of participants had a good perceived knowledge for sensitivity and specificity, and $44 \%$ for odds ratios. Perceived knowledge of relative risk was $56 \%$ in our sample as compared to $82 \%$ in the United States. More than $80 \%$ of respondents in this study reported a good perceived knowledge on case control studies. Windish $^{4}$ reported that only $39 \%$ of respondents in the US had a good perceived knowledge of case control studies and $59 \%$ of the respondents correctly interpreted the meaning of the pvalue. In our study, $48 \%$ of respondents reported a good perceived knowledge on p-value; for specialists and PG trainees it was more than $79 \%$.

The mean knowledge score of $57 \%$ reported in our study was higher than that reported by Windish ${ }^{4}$ (41.4\%) among doctors in the United States. However, Windish $^{4}$ assessed more advanced knowledge on statistics used in six general medical journals. Other studies have reported four or less correct answers out of nine ${ }^{3,5}$ or ten ${ }^{10}$ questions.

As in this study, several studies ${ }^{3,4,5,10}$ have reported that doctors with postgraduate qualifications had higher knowledge scores than grade medical doctors. Three studies $^{2,4,5}$ reported that respondents who had attended statistical workshops or courses previously had significantly higher knowledge scores than those who had not. Novack $^{10}$ had reported that doctors who read journal articles regularly had a higher knowledge score similar to the findings of this study. Significantly higher knowledge scores among male than female doctors was also reported by Windish ${ }^{4}$ which was consistent with our findings.

In this study, two scenarios to assess knowledge, and ability to interpret, relative risk, mean difference, 95\% confidence intervals and p-values were given to respondents. All three groups responded poorly to both scenarios giving an overall correct response rate of $25 \%$ and $20 \%$. These findings were similar to those reported by Windish ${ }^{4}$ among doctors in the US where only $12 \%$ interpreted the 95\% confidence interval and statistical significance correctly.

The results of this study should be interpreted with caution. By assessing perceived knowledge on epidemiological and statistical concepts, there is a possibility of overestimating one's knowledge. This was evident by the low scores obtained for the two scenarios which was a more objective way of assessing knowledge. We did not assess sophisticated concepts on epidemiology and biostatistics which appear more commonly in the current medical journals. However, the generalizability of the results to a wider medical community is questionable, as our sample was confined mainly to the teaching hospitals. . Based on the results of this study, we conclude that knowledge of doctors in Sri Lanka on epidemiological and bio-statistical concepts needs to be improved 
in order to enhance their ability to practice evidence based medicine. It is recommended that undergraduate curricula should stress more on these concepts by incorporating novel teaching methods which would inculcate lifelong learning skills among graduates. Continuing education in epidemiology and biostatistics through in-service training is another avenue to be explored. Thus, the inclusion of basic epidemiology and biostatistics modules in all postgraduate training courses must be given serious consideration.

Table 5 - Adjusted odds ratios for poor knowledge by participant characteristics

\begin{tabular}{lccc}
\hline Variable & $\begin{array}{c}\text { Odds } \\
\text { Ratio }\end{array}$ & $\begin{array}{c}\mathbf{9 5 \%} \\
\text { Confidence Interval }\end{array}$ & p value \\
\hline Male doctors & 0.39 & $0.23-0.65$ & $<0.001$ \\
Specialists and PG trainee & 0.34 & $0.19-0.60$ & $<0.001$ \\
Reading medical journals regularly & 0.49 & $0.26-0.93$ & $<0.05$ \\
\hline
\end{tabular}

\section{References}

1. De Vito C, Nobile CG, Furnari G, Pavia M, De Giusti M, Angelillo IF, Villari P. Physicians' knowledge, attitudes and professional use of RCTs and metaanalyses: a cross-sectional survey. The European Journal of Public Health.2009;9: 297 - 302.

2. Weiss ST, Samet JM. An assessment of physician knowledge of epidemiology and biostatistics. J Med Educ. 1980;55(8):692697.

3. Wulff HR, Andersen B, Brandenhoff P, Guttler F. What do doctors know about statistics? Stat Med. 1987;6(1):3-10.

4. Windish DM, Huot SJ, Green ML. Medical residents' understanding of the biostatistics and results in the medical literature. JAMA 2007;298(9):1010-22.

5. Laopaiboon M, Lumbiganon $\mathrm{P}$, Walter SD. Doctors' statistical literacy: a survey at Srinagarind Hospital, Khon Kaen University. J Med Assoc Thai. 1997;80:130-7.
6. West CP, Ficalora RD. Clinician attitudes toward biostatistics. Mayo Clin Proc. 2007;82(8):939-943.

7. Horton JN, Switzer SS. Statistical Methods in the Journal. N Engl J Med 2005;353:1977-1978.

8. Altman DG. Statistics in medical journals: some recent trends. Stat Med 2000;19:3275-89.

9. Al-Ansary LA, Khoja TA. The place of evidence-based medicine among primary health care physicians in Riyadh region, Saudi Arabia. Family Practice 2002;19: 537-542.

10. Novack L, Jotkowitz A, Knyazer B, Novack V. Evidence-based medicine: assessment of knowledge of basic epidemiological and research methods among medical doctors. Postgrad Med J. 2006;82:817-22. 